\title{
Chronic urticaria in adults: state-of-the-art in the new millennium*
}

\author{
Paulo Ricardo Criado ${ }^{1}$ \\ Celina Wakisaka Maruta ${ }^{1}$
}

\author{
Roberta Facchini Jardim Criado ${ }^{2}$ \\ Vitor Manoel Silva dos Reis ${ }^{1}$
}

\begin{abstract}
Chronic urticaria has been explored in several investigative aspects in the new millennium, either as to its pathogenesis, its stand as an autoimmune or auto-reactive disease, the correlation with HLA-linked genetic factors, especially with class II or its interrelation with the coagulation and fibrinolysis systems. New second-generation antihistamines, which act as good symptomatic drugs, emerged and were commercialized over the last decade. Old and new drugs that may interfere with the pathophysiology of the disease, such as cyclosporine and omalizumab have been developed and used as treatments. The purpose of this article is to describe the current state of knowledge on aspects of chronic urticaria such as, pathophysiology, diagnosis and the current therapeutic approach proposed in the literature.
\end{abstract}

Keywords: Angioedema; Biological factors; Colchicine; Cyclosporine; Dapsone; Immunosuppressive agents; Urticaria

\section{INTRODUCTION}

Acute urticaria and angioedema can be part of the clinical spectrum of anaphylaxis and thus present a lethal risk if left untreated. ${ }^{1}$ Chronic urticaria (CU) on the other hand is a disease with major negative impact on the patients' daily activities and can therefore worsen their quality of life.

Over the last decade, European consensus regulated the classification, diagnosis and treatment of this group of diseases, based on critical analysis of Evidence-Based Medicine (EBM). ${ }^{2}$

This review will approach relevant aspects of the "Position Paper of the Fourth International Consensus Meeting on Urticaria, Urticaria 2012", etiologic factors and pathophysiologic mechanisms associated with $\mathrm{CU}$ in the literature that were deemed relevant in the new millennium. ${ }^{2}$

\section{Physiopathologic mechanisms / Etiologic factors}

Urticaria is a cutaneous reaction characterized by a sudden pruriginous rash accompanied by erythema and edema, defined borders, location, size and shapes that lasts for a few hours and is linked to the release of chemical mediators, mainly histamine, from mast cells in the dermis. ${ }^{1}$ So, it is a heterogeneous group of diseases caused by or related to various factors, marked by the pattern of response with skin wheals/or angioedema. According to its evolution over time, it can be classified as acute ( $<6$ weeks) or chronic (> 6 weeks). ${ }^{2}$

Several etiologic factors have been associated with CU throughout history: thyroid diseases, pseudo-allergens, actual allergens, Helicobacter pylori infection, other infections/infestations and autoimmunity/autoreactivity.

\footnotetext{
Received on 05.03.2014.

Approved by the Advisory Board and accepted for publication on 04.06.2014.

Work performed at the Hospital das Clínicas da Faculdade de Medicina da Universidade de São Paulo (FMUSP) - São Paulo (SP), Brazil

Conflict of interest: None

Financial Support: None 
Helicobacter pylori infection and its relation to $\mathrm{CU}$ : Hizalet al demonstrated the positivity of autologous serum skin test (ASST) and high levels of IgG against Helicobacter pylori among patients with $\mathrm{CU}$ and concluded that the link between autoimmunity and infection by Helicobacter pylori warranted further studies. ${ }^{3}$

Federman et al. ${ }^{4}$ in an attempt to try and resolve this controversy, performed a literature review and selected ten relevant studies published in English that fulfilled the following criteria: (i) patients with $\mathrm{CU}$ only, (ii) exclusion of other known causes of urticaria through specific tests, (iii) initial diagnosis of $H$. pylori infection established by serology, urea test or endoscopy, and (iv) complete treatment of $H$. pylori with antibiotics. ${ }^{4}$ The authors observed that the resolution of $\mathrm{CU}$ was more likely after the $H$. pylori treatment had been completed, than if the patogen was not eradicated. About $50 \%$ of the population has serologic evidence of past or present $H$. pylori infections and at least $30 \%$ of $\mathrm{CU}$ patients are infected with this agent, but in general, the treatment of this bacterium does not influence the course of $\mathrm{CU} .{ }^{4}$

Greaves $^{5}$ suggested that $H$. pylori infection might have an indirect role in $\mathrm{CU}$ pathogenesis. Because of the immunogenicity of the patogen's cell envelope, it could be linked to the production of autoantibodies against Lewis $\mathrm{X}$ and $\mathrm{Y}$ blood group polysaccharide antigens, similar to that which occurs through molecular mimetism in Campylobacter jejunii infections and during Guillain-Barre syndrome. Therefore, $H$. pylori can have an indirect involvement in the etiology of $\mathrm{CU}$, by reducing the immune tolerance and inducing the formation of autoantibodies, including the production of autoantibodies to antiFceRIa. ${ }^{6}$

Based on these data, there is still no overall consensus that the investigation of $H$. pylori should be performed as a routine or, that when it is present, the treatment might influence the course of CU.

\section{Urticaria: food as a cause of pseudo-allergic reac- tions}

Tharp et $a l^{7}$ suggested that gastrin, a 17aminoacid peptide released by $G$ cells in the gastric antrum and proximal duodenum immediately after feeding, may be involved in anaphylactic reactions and urticaria reported after the ingestion of certain foods. This is corroborated by the observation that, it is not always possible to establish a direct correlation between clinical symptoms and the detection of antigen-specific IgE antibodies in cases of suspected food allergy?

In recurring $\mathrm{CU}$, it is assumed that there might be histamine intolerance caused by an excessive dose of histamine in the diet and/or by abnormal histamine metabolism (diamine oxidase deficiency).
Diamine oxidase is the main enzyme involved in the degradation of histamine, acting predominantly in the intestinal mucosa. Alcohol and some medications may decrease the activity of this enzyme and determine a higher sensitivity to histamine-rich or histamine-producing foods. Several experiments have demonstrated deficiency of diamine oxidase in enterocytes of patients with recurrent $\mathrm{CU}{ }^{8}$

Certain fishes (tuna, sardines, anchovies), cheeses (Emmenthal, Gouda), salami, sausage, certain fruits and vegetables (tomatoes), wine and beer are histamine-rich foods. ${ }^{9}$ Drugs that may inhibit the intestinal activity of diamine oxidase and determine a higher concentration of histamine in general are: imipenem, dobutamine, pancuronium, pentamidine, salazosulfapyridine, verapamil, isoniazid, clavulanic acid, dihydralazine, chloroquine, cycloserine, acetylcysteine, metoclopramide and cefuroxime. ${ }^{9,10}$

Food additives such as preservatives, dyes and natural salicylates may trigger or aggravate urticaria through pseudo-allergic non-IgE-dependent mechanisms. These additives are: sodium metabisulfite, sodium benzoate, monosodium glutamate (MSG), sodium nitrate, tartrazine, erythrosine, sorbic acid and butylated hydroxyanisole. ${ }^{10}$ Regarding MSG, there is still no definitive conclusion about its causal relation to chronic urticaria, despite the existence of controlled studies. ${ }^{11}$

Di Lorenzo et $a l^{12}$ studied pseudo-food allergy in 838 patients with chronic/recurrent idiopathic urticaria and found it present in about 1.0 to $3.0 \%$ of their population. The provocation tests with doubleblind placebo-controlled technique were performed using the following substances: tartrazine (E102), erythrosine (E127), monosodium benzoate (E211), phydroxybenzoate (E218), metabisulfite (E223) and monosodium glutamate (E620). The authors recommend considering the possibility of exclusion diets and provocation tests with food additives in cases of $\mathrm{CU} /$ refractory angioedema that fail to fully respond to $\mathrm{H}_{1-}$ antihistamine treatment. The general consensus is that, regarding $\mathrm{CU}$, food additives can aggravate the disease but they are rarely its sole cause.

\section{Dental infections and urticaria}

The connection between dental infections and CU remains unclear. ${ }^{13}$ There have been reports of transient urticaria with high fever outbreaks after dental treatment, suggesting that bacteremia and/or toxemia arising from treatment would induce urticaria through immune and non-immune mechanisms. Histamine release by mast cells, secondary to lipopolysaccharides from oral flora Gram-negative bacteria such as Veilonellasp, could be relevant as a pathogenic factor in urticaria outbreaks in patients with odontogenic infection; furthermore, these ana- 
phylotoxins can have an acute direct vasodilator effect that determines urticaria outbreaks. ${ }^{13}$ We believe that patients with urticaria should have their dental condition assessed.

\section{Hepatitis B and C infection}

The fact that hepatitis B may be the cause of wheals or hives, particularly acute urticaria or CU is already well established. ${ }^{14}$ It has been widely debated that hepatitis $\mathrm{C}(\mathrm{HC})$ can cause hives. We concur with the opinion of Siddique et al, that patients with urticaria living in areas of high prevalence of HC infection should be screened for it..$^{15}$

\section{Helminthic parasites and infestations}

The association of acute urticaria and angioedema or CU with infestations by parasitic, protozoa, ectoparasites and helminthes has been postulated for many decades. In fact, the literature is replete with case reports or case series, but there are few case-control studies or meta-analyses on this subject. The association of urticaria with the following parasites have been reported: Giardia lamblia, Fasciola hepatica, Toxocara canis, Echinococcus granulosus, Strongyloides stercoralis, Hymenolepis nana, Blastocystis hominis, Ascaris lumbricoides, Anisakis simplex, Cimexlectularius (bedbug), Argas reflexus (bird tick). ${ }^{16-26}$

The association between parasitism and urticaria has been better established with Anisakis simplex and recently with Blastocystis hominis. Anisakis simplex, also known as Pseudoterranova decipiens, Terranova decipiens or Phocanema decipiens belongs to the Anisakidae family. ${ }^{27}$ These nematodes have been described in infestations affecting humans after the ingestion of raw or not fully cooked seafood. ${ }^{27}$ Anisakiasis is the term used to describe the acute form of the disease in humans. Seafood is the main source of larval infection. Aside from urticaria and anaphylaxis, other manifestations such as rheumatic symptoms, contact dermatitis, Crohn's disease, eosinophilic gastroenteritis, conjunctivitis, and asthma have been reported. ${ }^{27}$ Sensitization to Anisakis simplex can be investigated through specific RAST test in peripheral blood.

The prevalence of Blastocystis hominis ranges from $10 \%$ in developed countries to $50 \%$ in those in process of development. ${ }^{28}$ Several authors have correlated different Blastocystis hominis genetic subtypes especially subtype 3 - with cases of CU and acute urticaria, a fact that was not confirmed by other researchers. ${ }^{28}$ Apparently the subtype identified may vary according to the different regions of the world, climate or seasonal changes, and source of infection. ${ }^{28}$ Therefore, cases of CU in highly endemic geographic areas should be investigated for Blastocystis hominis in the stool and if the diagnosis is confirmed, treatment should be prescribed with metronidazole.

\section{Chronic urticaria and thyroid}

Hashimoto's thyroiditis and Graves' disease are associated with idiopathic CU. ${ }^{29,30}$ Antithyroid antibodies are found in $27 \%$ of patients with idiopathic CU and $19 \%$ of patients have abnormal thyroid function. ${ }^{31}$ In such CU cases, high titers of antithyroid antibodies (antithyroglobulin and antiperoxidase) can be detected, while that occurs in only about $3 \%$ to $4 \%$ in the general population without thyroid diseases. ${ }^{32}$

The simultaneous occurrence of antithyroid antibodies and anti-FceRI $\alpha$ in some patients with socalled "idiopathic" urticaria seems to indicate the existence of a disease or a "state" secondary to an underlying autoimmune process and/or a disruption of immune regulation. Rottem (2003) reinforces this concept, suggesting that there are no data to support a connection between the presence of antithyroid antibodies and CU's pathogenesis, and that these are most likely parallel events, as occurs with autoimmune diseases. ${ }^{33}$ In conclusion, tests for antithyroid antibodies and thyroid function should be performed in all CU cases in order to detect early those thyroid dysfunctions that require follow-up and treatment. ${ }^{33}$

\section{Autoimmune / auto-reactive chronic urticaria}

About $50 \%$ of the cases of chronic urticaria are considered autoimmune diseases, due to the presence of circulating histamine-releasing autoantibodies, especially directed against IgE high-affinity receptors (FceRI $\alpha$ ) present in the cytoplasmic membrane of mast cells and basophils or anti-IgE autoantibodies. ${ }^{34}$ There is clear evidence for a genetic predisposition to develop CU, i.e., there is a strong association with HLA and familial inheritance or autoimmune etiology in some cases, especially those with a positive autologous serum skin test (ASST). ${ }^{34}$ There are reports suggesting a connection between $\mathrm{CU}$ with a positive ASST result and autoimmune diseases, such as autoimmune thyroiditis, celiac disease, rheumatoid arthritis, Grave's disease and type 1 diabetes mellitus; also, a higher frequency of autoimmunity serum markers like rheumatoid factor, antinuclear and antithyroid antibodies. ${ }^{34}$ Patients with CU and positive ASST have a high frequency of HLA-DRB1 * 04 and its associated allele DQB1 * 0302 when compared to the healthy population and patients with CU and negative ASST. ${ }^{34-36}$

Unfortunately, we still lack a routine laboratory test to detect anti-FceRI $\alpha$ and / or circulating and functionally active anti-IgE. ASST autoantibodies have been considered an "in vivo" test to confirm both the presence of these autoantibodies and histamine 
release in basophils. ${ }^{34,36}$

In a retrospective study performed in Israel, Confino-Cohen et $a l^{36}$ analyzed data from 12,778 patients with $\mathrm{CU}$ during a period of 17 years, and compared clinical and laboratory data with 10,714 control patients without CU. There was a definite increase in the odds ratio of hypo-or hyperthyroidism and the presence of antithyroid antibodies among patients with CU. Female patients with CU had a higher incidence of rheumatoid arthritis, Sjögren's syndrome, celiac disease, type I diabetes mellitus and systemic lupus erythematosus during their lifetime and those illnesses were diagnosed mainly in the 10 years following the diagnosis of CU. Increase in mean platelet volume, positivity for rheumatoid factor and antinuclear antibodies were more prevalent and significant among patients with CU. Probably the presence of a chronic inflammatory process, implied by the increased mean platelet volume, shares a common pathogenic pathway with autoantibody formation in patients with CU. However, $50-60 \%$ of CU cases remain idiopathic, the so-called "spontaneous" CU.,36 Recently, some authors demonstrated the activation of the coagulation system in patients with $\mathrm{CU}$ via thrombin generation, initiated by the increased expression of coagulation tissue factor on eosinophils. ${ }^{37-39}$ This determines a potential contribution to the increase in capillary permeability. These patients often have elevated coagulation and fibrinolysis serum markers, such as fragment $1+2$ prothrombin and D-dimer, whose levels seem to correlate with the severity of CU. ${ }^{37-39}$ In animal models, thrombin shows increased capillary permeability by direct action on the endothelium and indirectly by inducing the release of pro-inflammatory mediators by mast cells, increasing $\mathrm{C} 5 \mathrm{a}$ in the absence of $\mathrm{C} 3$, and bypassing the first part of the complement cascade. ${ }^{37-39}$ It is possible that, a synergy between the action of autoantibodies and the coagulation cascade exists in some patients with chronic urticaria. ${ }^{37}$

An article by the "European Academy of Allergy and Clinical Immunology" was published in 2013, defining and proposing criteria for the diagnosis of autoimmune urticaria. ${ }^{40}$ The following criteria were proposed as the gold standard for autoimmune chronic urticaria: ${ }^{40}$ (a) presence of a positive in vitro biological test to demonstrate the autoantibodies' functionality (basophil histamine release test or the expression of a basophil activation marker such as CD63 or better still, CD203c during flow cytometry) AND (b) positive autoreactivity (positive ASST) in order to demonstrate the in vivo relevance of mast cell degranulation and the increase in capillary permeability, AND (c) a positive immunological assay for autoantibodies against FceRI $\alpha$ receptors (Western blot or ELISA), to demonstrate the autoantibodies' specificity.

In daily practice, however, most physicians have only the autologous serum skin test available and its positivity in a patient with CU can only suggest "autoreactivity". Unfortunately, we do not have the other tests indicated for the diagnosis of autoimmune $\mathrm{CU}$ in our country.

\section{Chronic urticaria and allergic etiology}

The link between CU, IgE sensitization, aeroallergens and allergy has been much discussed but seldom studied. ${ }^{41}$

Between 2006 and 2008, in France, Augeyet al ${ }^{41}$ studied 128 adult patients with CU under the aspects of IgE sensitization and allergy. These authors considered CU an allergic disease if: i) there was a high correlation of positive prick tests (skin puncture tests) to an allergen that was clinically relevant in the patient's medical history, and ii) a complete remission of urticaria occurred within the first two months after the allergen was removed. Among 105 patients with interpretable puncture tests, $46.7 \%$ were sensitized by IgE. Two patients had clinically relevant puncture tests, however their $\mathrm{CU}$ had many other triggering factors and there was no remission after withdrawal from allergen exposure. The authors concluded that the rate of $\operatorname{IgE}$ sensitization is higher among patients with $\mathrm{CU}$, compared to the general adult population. ${ }^{41}$ However, these CU cases cannot be considered as an expression of IgE-mediated allergies, but as a chronic inflammatory disease that is more common in IgE sensitized subjects and induced by many factors, amongst which IgE-mediated allergy is the least frequent one. ${ }^{41}$

The relevance of allergic sensitization to dust mites in the etiology and treatment of $\mathrm{CU}$ is still unknown. In Turkey, Caliskaner et al ${ }^{42}$ studied 259 patients with chronic urticaria and angioedema, without respiratory allergic diseases (rhinitis and/or asthma) and compared their results with 300 healthy controls and 300 atopic patients. Immediate cutaneous reactivity to one or more allergens was detected in 71 cases of CU and angioedema (27.4\%). The most commonly detected allergen was residential house dust $(24.7 \%))^{42}$ Positive prick tests (skin puncture tests) were correlated to other aeroallergens, including pollen, mold and cockroaches in $7.7 \%, 0.4 \%$ and $0.8 \%$ of patients respectively. In the healthy control group, $7 \%$ of cases were considered atopic regarding the prick test results. ${ }^{42}$ Pollen (6\%) and house dust (4.7\%) were the most commonly found allergens in the healthy control group. In the atopic control group, pollen and dust mites were the allergens most commonly detected in the prick test $(62 \%$ and $50.3 \%$, 
respectively). ${ }^{42}$ The difference between patients with $\mathrm{CU}$ and the control group was statistically significant, regarding the presence of atopy and sensitivity to mites $(\mathrm{p}<0.001){ }^{42}$ The proportion of skin test that were positive to house dust was higher in the $\mathrm{CU}$ group than among healthy cases, but not as high as in atopic patients. ${ }^{42}$ Furthermore, the rate of cutaneous reactivity to other aeroallergens did not differ from the healthy group. The authors concluded that urticaria, as an isolated clinical manifestation in patients who are sensitive to dust, was not common in this study.

Therefore, it is well established that $\mathrm{CU}$ is not included in the indications for immunotherapy with allergy desensitization..$^{42}$ So, in our opinion, the systematic practice of skin prick test reading should not be routinely performed during the investigation of $\mathrm{CU}$, unless there is a definite correlation between episodes of CU worsening and data from the patient's medical history.

\section{Definition, classification and course of the disease}

Urticaria is characterized by the sudden appearance of wheals, which may be accompanied by angioedema. ${ }^{43,44}$ Superficial dermal edema is called wheals or hives, while edema in the deep dermis, hypodermis and gastrointestinal tract is known as angioedema. ${ }^{44,45}$ Diagnosis is mainly clinical. ${ }^{1}$

Wheals have three typical features: (i) central edema of variable size, almost always surrounded by a reflex erythema, (ii) association with pruritus and sometimes a burning sensation, (iii) ephemeral nature, with the skin returning to its regular appearance in usually 1 to 24 hours. Angioedema is characterized by: (i) a sudden, pronounced edema of the deep dermis and subcutaneous tissue: (i) pain more often than pruritus (iii) frequent involvement of mucous membranes, and (iv) resolution of symptoms in about 72 hours, more protracted than in the case of wheals.

It is well known that, the spectrum of clinical manifestations of the different subtypes of urticaria is very broad. Moreover, two or more subtypes of urticaria can coexist in the same patient. During the "4th International Consensus Meeting on Urticaria 2012", the adoption of a clinical classification (shown in chart 1) was proposed. ${ }^{2}$

Undoubtedly, this classification is not perfect since there are still some inconsistencies, e.g., physical urticaria also has a chronic nature. ${ }^{42}$ However, physical urticarias are grouped as a result of the special nature of their causal factors, while in acute and chronic urticarias, lesions appear spontaneously without external physical stimuli. ${ }^{3}$

In 2001, Kozelet a ${ }^{43}$ published a study conducted in the Netherlands, with 220 adults diagnosed with urticaria. Of these, 72 cases $(33.2 \%)$ had physical urticaria, $24(10.9 \%)$ had a combination of physical urticaria and idiopathic CU, 78 (36\%) had idiopathic CU, 20 cases $(9.0 \%)$ were induced by drugs, $15(6.8 \%)$ by food, four $(1.8 \%)$ by infections, three $(1.4 \%)$ by internal diseases, and two $(0.9 \%)$ were urticaria due to contact. Causality was established in $53.1 \%$ of the cases. Thirty-five percent of the cases were free of symptoms after one year and in $28.9 \%$ there was an improvement of symptoms. Spontaneous remission occurred in $47.4 \%$ of patients in whom no causal agent was identified and only in $16.4 \%$ of cases with physical urticaria. In this study, patients with physical urticaria had the worst prognosis regarding disease duration, as $84 \%$ of them still had symptoms after one year. ${ }^{43}$ Another important factor in urticaria is to classify the intensity and activity of the disease. Młyneket $a l^{44}$ proposed a classification, later validated in 2008, which was ease to adhere to by both physicians and patients in their daily activities (Chart 2). ${ }^{4}$ Due to the variable intensity pattern of urticaria along the day, sequential dermatologi-

CHART 1: Classification of urticaria according to duration, frequency and causes

\begin{tabular}{|c|c|c|c|}
\hline \multicolumn{2}{|c|}{ Type of urticaria } & \multicolumn{2}{|c|}{ Duration: } \\
\hline \multicolumn{4}{|c|}{ Spontaneous urticaria: } \\
\hline 1. & Acute urticaria & 1. & Less than six weeks \\
\hline 2. & Chronic urticaria: & 2. & More than six weeks \\
\hline \multicolumn{4}{|c|}{ Unknown etiology } \\
\hline \multicolumn{4}{|c|}{ Induced urticaria: } \\
\hline (i) & Dermographism & (i) & Application of mechanical forces to the skin (wheals appear in 1 to 5 minutes). \\
\hline (ii) & Delayed pressure urticaria & (ii) & (ii) Vertical pressure (wheals appear after 3 to 8 hours of latency). \\
\hline (iii) & Urticaria secondary to cold & (iii) & Cold air/ water / wind. \\
\hline (iv) & Urticaria secondary to heat & (iv) & Localized heat. \\
\hline (v) & Solar urticaria & (v) & Ultraviolet (UV) and orvisible light \\
\hline (vi) & Urticaria/ vibratory angioedema & (vi) & Vibratory forces, usually pneumatic devices. \\
\hline (vii) & Aquagenic urticaria & (vii) & Contact with water, regardless of its temperature. \\
\hline (viii) & Cholinergic urticaria & (viii) & Stress, perception of body temperature elevation by the hypothalamus. \\
\hline (ix) & Contact urticaria & (ix) & Allergic or pseudo-allergic \\
\hline
\end{tabular}

Adapted from Zuberbier $\mathrm{T}$ et $\mathrm{al}^{2}$ 
CHART 2: Assessment of intensity (clinical activity) of urticaria

\begin{tabular}{|cll|}
\hline SCORE* $^{*}$ WHEALS & PRURITUS \\
\hline $\mathbf{0}$ & Absence of wheals & Absence of symptoms \\
$\mathbf{1}$ & Light $(<20$ wheals / 24 hours) & Light \\
$\mathbf{2}$ & Moderate (21-50 wheals/24 hours) & Moderate \\
$\mathbf{3}$ & Severe ( $>50$ wheals /24 hoursor large confluent areas with wheals) & Intense \\
\hline
\end{tabular}

*Score sum (wheals+pruritus) $=(0-6)$. Adapted from Zuberbier Tet $\mathrm{al}^{2}$

cal inspections (visualization of the skin) should be made periodically (Urticaria Activity Score - UAS 0-6 points) to increase the accuracy of the score; the sum of points scored over seven days (UAS 7, 0-42 points) is currently being used in clinical studies. ${ }^{44}$ In general, larger wheals indicate outbreaks that are more intense and more difficult to treat. ${ }^{44}$

\section{DIAGNOSIS}

Spontaneous UC is a disease that causes serious impact on patients and high direct and indirect costs to the health system, as well as extensive socioeconomic implications, since it delays by about $20-30 \%$ the return of productive individuals to the work force. ${ }^{2}$ Due to the wide heterogeneity of this group of diseases called urticaria, routine investigation should include a good history, a good physical exam, quests for information on possible causal factors and important data on the nature of urticaria. ${ }^{2}$ The next step is laboratory testing to exclude significant systemic diseases, provided they are warranted by clinical history and physical examination. ${ }^{2}$

Skin biopsy of wheals must be performed if there is suspicion of vasculitis or urticaria vasculitis, which usually persists for more than 24 hours in the same location and can leave hyperchromic or purplish residual lesions, although that does not always occur. ${ }^{2,45}$ Furthermore, burning symptoms isolated or coupled with pruritus may be reported by these patients. Skin biopsy of wheals is also indicated in cases that are refractory to treatment with antihistamines. ${ }^{2,45}$

\section{Considerations on autologous serum skin test (ASST)}

In 1946, Malmros published the first report on the likelihood of autologous serum (from patients with urticaria) triggering positive skin tests, although this hypothesis was disregarded for decades. ${ }^{46}$

The autologous serum skin test (ASST) is an "in vivo" test that measures the autoreactivity of an individual. $^{40,47}$ This autoreaction is characterized by the formation of wheals and pruritus in response to an intradermal injection of autologous serum (obtained from the patient during the clinical activity of urticaria, or crisis), which acts indirectly through the release of mediators from mast cells/other cells or directly by acting on the skin's microvasculature. ${ }^{40,47}$ It should be stressed that, autoreactivity does not define nor does it imply in the presence of autoimmune urticaria, but it may be an indication of mast cell activation by the autoantibodies present in the autologous serum of patients with CU and positive ASST. ${ }^{40,47}$

The frequency of positive ASST in adults with $\mathrm{CU}$ ranges from $4.1 \%$ to $76.5 \%$ depending on different criteria for positivity, including confirmation by histamine release test (HRT). ${ }^{40}$ The discrepancy in results can be attributed to patient selection bias, severity of illness, methodology and interpretation of the results or even the actual prevalence of autoimmune urticaria in the population tested..$^{40}$ The frequency of positive ASST is $45.5 \%$ (95\% CI, 24.7-74.4\%) when establishing a $1.5 \mathrm{~mm}$ difference in diameter between the response obtained with cases tested with saline (negative control) and $43.5 \%$ (95\%CI, 34.8-62.1\%) when the difference is $2 \mathrm{~mm}^{47} \mathrm{~A}$ positive ASST result on a CU case could mean an "auto-reactive CU".40

Current recommendations to establish the methodological standardization for ASST are summarized in Figure $1{ }^{40}$ In order to perform an ASST, it is necessary to take the patient off any medication with antihistamine activity for a variable period of time before testing, as depicted on chart $3 .^{40}$

\section{Considerations on the autologous plasma skin test (APST)}

The autologous serum skin test is based on intradermal injection of autologous serum, and merely represents a diagnostic procedure used in autoimmune CU. ${ }^{48,49}$ The plasma used in the APST also contains coagulation factors and sodium citrate. Therefore, the positivity occurring in the APST may be due both to autoantibodies that induce thrombin activity and/or to the sodium citrate. ${ }^{48}$

In a study with 96 patients with CU, Asero et $a l^{49}$ found that 51 of 96 patients (53\%) were ASST-positive, and 61 of $71(86 \%)$ were APST-positive. Asero's group in Italy advocates that, the autologous plasma skin test increases the sensitivity of diagnosis in cases of autoreactive $\mathrm{CU}$, since it indicates the activation of the coagulation cascade in the presence of autoantibodies. These autoantibodies, when degranulating mast cells and basophils, activate eosinophils, which in turn release tissue factor thus stimulating the coagulation cascade and compensatory fibrinolysis. The latter will 


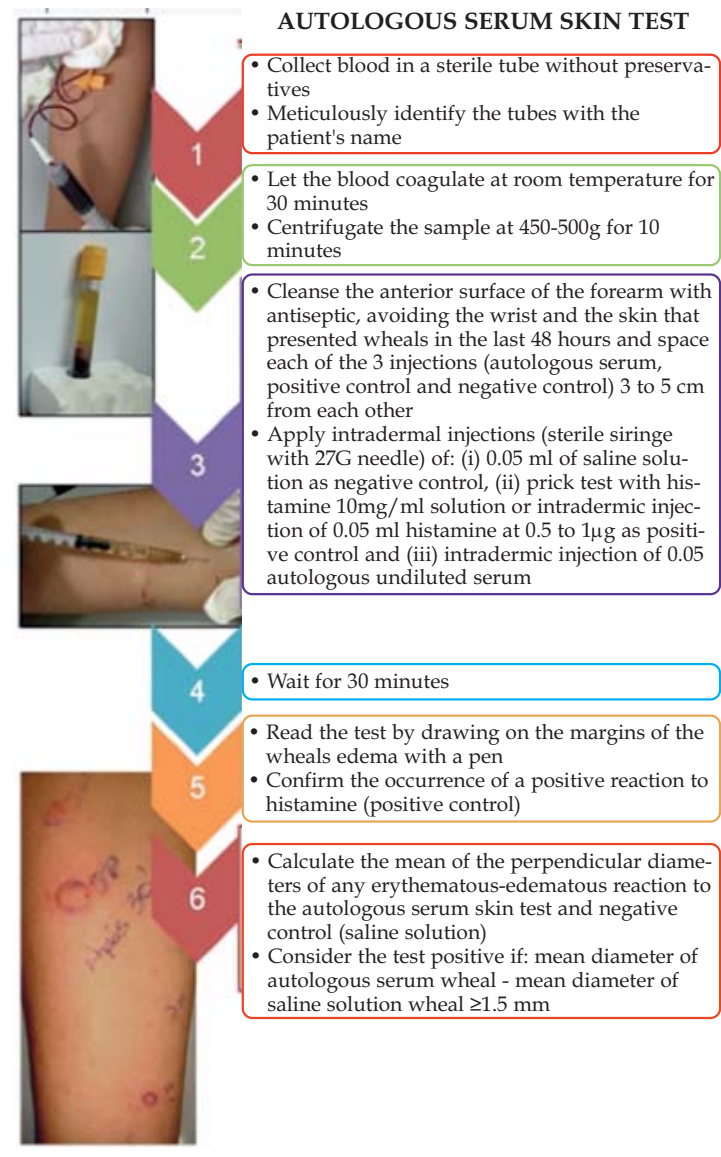

FIGURE 1: Method of execution of the autologous serum skin test generate thrombin, which will induce the activation of more mast cells and the vascular endothelium; also ddimers are detected at higher levels as a final result of fibrinolysis.

In another multicentre study, ${ }^{50}$ the positivity rate was 37.5\% for ASST and 43\% for APST among 200 patients with CU (146 women and 54 men).

Yildizet al. ${ }^{51}$ studied 42 patients (19 males, 23 females, mean age: 35.7 , range: $28-76$ years) and 35 healthy volunteers (19 males, 16 females, mean age: 30.28, range: $20-80$ years). The authors performed APST, ASST, negative control with saline and sodium citrate and positive control with histamine. In terms of positivity, no statistically significant difference between APST and ASST was found..$^{51}$ Therefore, the authors concluded that APST to assess autoreactivity in clinical practice was not superior to ASST and further studies should be conducted to corroborate these findings.

\section{TREATMENT}

The treatment of urticaria includes pharmacological and non-pharmacological interventions. ${ }^{52,53}$ Non-pharmacological interventions for physical urticaria are limited to reduction of stress levels, and sun exposure and diminished alcohol intake. There is little evidence that reducing drug-intake and the exposure to pseudo-allergens would improve urticaria in these patients, except in cases of spontaneous $\mathrm{CU}$, which is aggravated by nonsteroidal anti-inflammatory drugs (especially aspirin) in $25-30 \%$ of patients with urticaria. ${ }^{52}$ Cooling lotions, such as $1 \%$ menthol can be soothing to many patients with very active urticaria. ${ }^{52}$

СHART 3: Suppression of urticated response after prick test with histamine by different medications with anti-H1 activity

\begin{tabular}{|c|c|c|c|}
\hline \multirow[t]{2}{*}{ Drug/daily dose } & \multirow{2}{*}{$\begin{array}{l}\text { Elimination } \\
\text { T } 1 / 2 \text { (h) }\end{array}$} & \multicolumn{2}{|c|}{$\begin{array}{l}\text { Length of suppressionof urticated response } \\
\text { secondary to histamine prick test }\end{array}$} \\
\hline & & Single dose (h) & Continuous use (days) \\
\hline Acrivastine $8 \mathrm{mg}$ & $1,4-3,1$ & 8 & UD \\
\hline Azelastine & 22 & 12 & 7 \\
\hline Cetirizine 10mg & $7-11$ & $\geq 24$ & 3 \\
\hline Cyproheptadine $8 \mathrm{mg}$ & UD & UD & 11 \\
\hline Dexchlorpheniramine $4 \mathrm{mg}$ & UD & UD & 4 \\
\hline Diphenhydramine & $9,2 \pm 2,5$ & UD & UD \\
\hline Ebastine 10mg & $10,3 \pm 19,3$ & $\geq 24$ & 3 \\
\hline Fexofenadine $60 \mathrm{mg}$ & 14,4 & 24 & $2^{*}$ \\
\hline Hydroxyzine $0,7 \mathrm{mg} / \mathrm{kg}$ & $20 \pm 4,1$ & 26 & UD \\
\hline Loratadine $10 \mathrm{mg}$ & $7,8 \pm 4,2$ & 24 & 7 \\
\hline Mizolastine 10mg & 12,9 & 24 & UD \\
\hline Levocetirizine $5 \mathrm{mg}$ & $7 \pm 1,5$ & UD & 4 \\
\hline Desloratadine $5 \mathrm{mg}$ & 27 & UD & UD \\
\hline Doxepin $25 \mathrm{mg}$ & 17 & 4-6 (days) & UD \\
\hline
\end{tabular}


In our opinion, it is important in the treatment of chronic urticaria to make the patient understand the need for continuous, and not intermittent treatment, in order to achieve the proper control of the disease; also, to explain that this is a chronic condition that requires uninterrupted medication similarly to hypothyroidism or diabetes mellitus, although unlike these two diseases, urticaria tends to go into remission over time.

Treatment of wheals outbreaks is sequential or made in steps, but its main cornerstone is the use of antihistamines (Figure 2). ${ }^{52}$ Therefore, H1 antihistamines (anti-H1) are crucial in the treatment of urticaria. ${ }^{52,53}$ Nevertheless, some CU cases may present a marked inflammatory cell infiltration, which can be somewhat refractory to anti-H1 and respond satisfactorily to oral corticosteroids or second-line agents (montelukast, dapsone or colchicine). ${ }^{52-54}$

Criado et al ${ }^{55}$ studied $22 \mathrm{CU}$ patients unresponsive to conventional antihistamine treatment. The patients had uncontrolled urticaria even with multiple combinations of antihistamines at maximum doses and corticosteroids for short cycles (prednisone 20-40 mg, p.o, once a day, 3-7 days per month). Cutaneous biopsies of the wheals were performed. The findings were classified as: (i) dermal perivascular mixed inflammatory infiltrate comprised of lymphocytes, monocytes and neutrophils and/or eosinophils; (ii) inflammatory infiltrate formed mainly by neutrophils; and (iii) inflammatory infiltrate composed mainly of eosinophils. According to histopathologic results, patients were subjected to one of the following regimens: Class A - antihistamine associated with dapsone; Class B - colchicine or dapsone; Class C - montelukast. Four patients in class A, eight in class B and seven in class $\mathrm{C}$ showed complete remission of urticaria after 12 weeks of treatment; one patient of class $B$ and two in class $C$ did not respond to therapy. Two years after treatment discontinuation, 16 patients remained urticaria-free. The authors concluded that, dapsone or colchicine might be effective adjuvant drugs in the presence of intense neutrophilic infiltrate, as could montelukast in cases with eosinophilic infiltrate.

H1-antihistamines are used in the treatment of urticaria since $1950 .{ }^{56}$ Although first-generation drugs have a relatively lower cost than second-generation ones, the former have pronounced anticholinergic effects, with sedative action on the central nervous system (CNS) that lasts 12 hours, while their anti-pruritic effects last between 4 to 6 hours. ${ }^{56}$ As a consequence, there have been many reports on interactions between first-generation anti-H1 drugs, alcohol and medications (analgesics, hypnotics, sedatives and antidepressant drugs), causing unwanted effects in the CNS. ${ }^{56,57}$ In addition, monoamine oxidase inhibitors may prolong and intensify the anticholinergic effects of first generation H1-antihistamines. ${ }^{54}$

The most used first-generation, anti-H1 drugs to treat $\mathrm{CU}$ belong to the groups of ethanolamines (diphenhydramine, clemastine), piperazines (hydroxyzine, dexchlorpheniramine) and piperidines (cyproheptadine and ketotifen). ${ }^{56}$ Some randomized studies compared the effects of cetirizine versus hydroxyzine and loratadine in the treatment of $\mathrm{CU}$ and demonstrated similar clinical efficacy but superior safety profile for cetirizine in comparison to hydroxyzine. The main differences between first and second-generation anti-H1 are listed in chart $4 . .^{57,58}$

Second-generation H1-antihistamines are the only drugs for the treatment of chronic urticaria, which are supported by high levels of scientific evi-

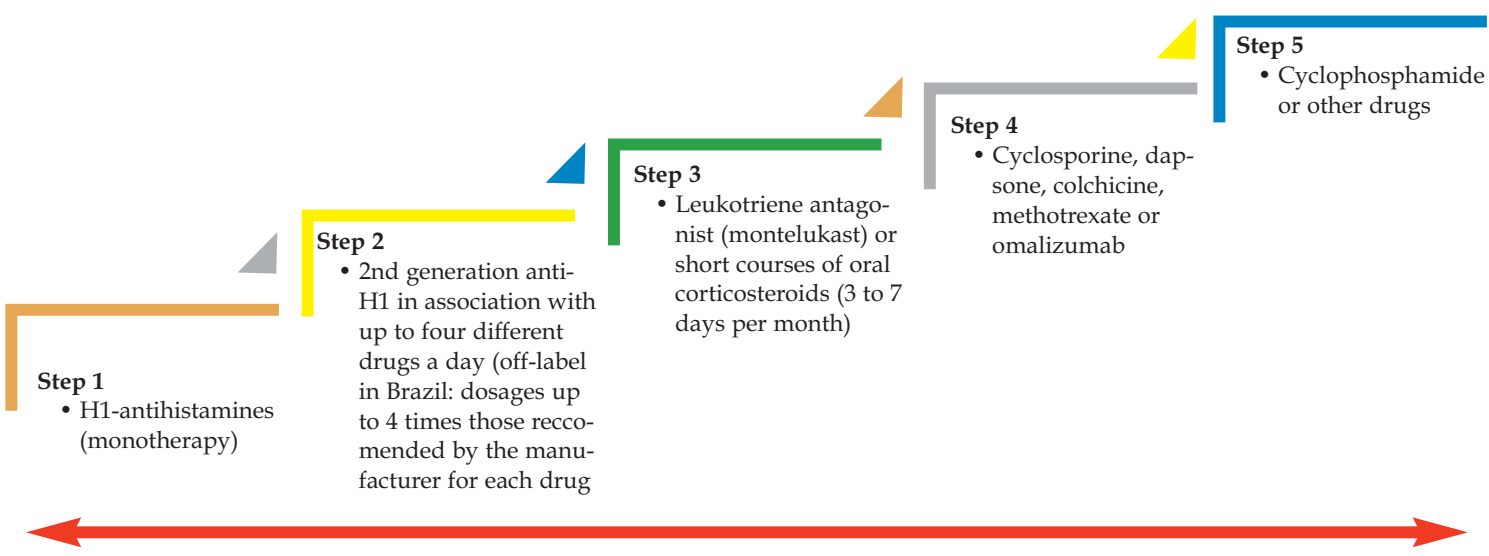

FigURE 2: Sequential treatment of Chronic Urticaria (in steps) 
CHART 4: Differences between first and second-generation anti-H1

\begin{tabular}{|ll|}
\hline First-generation H1Antihistamines & Second-generation H1Antihistamines \\
\hline $\begin{array}{l}\text { Usually given } 3 \text { to } 4 \text { times a day } \\
\begin{array}{l}\text { Cross the blood-brain barrier (they are lipophilic substances, have low } \\
\text { molecular weight and are not substrates of the P-glycoprotein efflux } \\
\text { pump system) }\end{array}\end{array}$ & $\begin{array}{l}\text { Usually given once or twice a day } \\
\text { Do not cross the blood-brain barrier (they are lipophobic } \\
\text { substances, have high molecular weight, and are substrates } \\
\text { of the P-glycoprotein efflux pump system) }\end{array}$ \\
$\begin{array}{l}\text { Cause several adverse events (sedation, hyperactivity, insomnia and } \\
\text { seizures) }\end{array}$ & $\begin{array}{l}\text { Do not cause significant adverse events in the absence of } \\
\text { drug interactions }\end{array}$ \\
$\begin{array}{l}\text { Case reports on toxicity are regularly published. } \\
\text { Absence of placebo-controlled, randomized, double-blind clinical trials }\end{array}$ & $\begin{array}{l}\text { Reports on serious toxicity events are virtually non-existent. } \\
\text { Some placebo controlled, randomized, double-blind clinical } \\
\text { trials, even in children }\end{array}$ \\
Lethal dose already identified in infants and children & No report of fatality due to overdose
\end{tabular}

Edited from Criado PR et $\mathrm{al}^{53}$ \& De Benedictis FM, De Benedictis D, Canonica, GW. (2008), New oral H1 antihistamines in children: facts and unmeet needs. Allergy, 63: 1395-1404. doi: 10.1111/j.1398-9995.2008.01771.x

dence, from the perspective of evidence-based medicine, as there are prospective, randomized and double-blinded controlled studies published. ${ }^{2,57}$ Therefore, these medications are indicated as first-line treatment for symptomatic $\mathrm{CU} .^{2}$ Second-generation antihistamines provide moderate-to-good control for $44-91 \%$ of all types of urticaria and $55 \%$ of patients with $\mathrm{CU} .{ }^{59}$ In general, all H1-antihistamines are effective in reducing pruritus in urticaria, although less often affecting the number and size of wheals. ${ }^{60}$ So, there is a sizable group of patients with CU for whom H1antihistamines in doses usually recommended on label are not able to control disease symptoms.

Some authors propose that, in young adults without associated disease, the doses of second generation anti-H1 should be increased up to four times those recommended by manufacturers on label, before substituting the drug or adding another medication in the treatment of CU (not approved by the National Health Surveillance Agency - ANVISA in Brazil). 2,53,53,61

A study using cetirizine in 22 patients with $\mathrm{CU}$ confronted these recommendations, seen as no improvement was observed after two weeks of treatment with $30 \mathrm{mg}$ of cetirizine, though this may be due to the limited observation period during the study. ${ }^{59}$

Weller et $a^{62}$ conducted a retrospective questionnaire survey on 319 patients diagnosed with spontaneous CU. The aim of this study was to establish the patient's perception on the effectiveness and adverse events of treatment with H1-antihistamines, both in standard and higher doses. Of the total population, 121 patients received questionnaires from their doctors or hospitals and 198 were informed about the research over the Internet, at the Allergie-Centrum-Charitè homepage or at the Urticaria Network (www.urtikaria.net) webpage. The latter group completed the questionnaire online. ${ }^{62}$ Both questionnaires were identical. All surveys were completed anonymously and no Internet Protocol (IP) was retrieved. The only pre-requisite for participation was that subjects had spontaneous CU (spontaneous wheals recurring for more than six weeks) and that they were adults, over 18 years of age. Participants agreed that the usual doses of second-generation antihistamines (recommended by the manufacturer) were significantly more effective than those of the first-generation drugs $(p<0.005) .{ }^{62}$ Furthermore, they found that second-generation drugs caused significantly fewer side effects $(p<0.001)$ and less sedation than first-generation antihistamine medications $(p$ $<0.001) .{ }^{62}$ Three quarters of the patients reported that they had increased the doses of second-generation antihistamines, and $40 \%, 42 \%$ and $54 \%$ of the subjects reported significantly higher benefits by taking 2,3 or 4 tablets per day, respectively. ${ }^{62}$ The number of reports on adverse events and sedation with higher doses was not significantly different from those reported with usual doses. ${ }^{62}$

In a literature review study, Sánchez-Borges et $a l^{63}$ concluded that the use of higher second-generation anti-H1 doses increased the proportion of patients who achieved the control of urticaria symptoms, without producing higher rates of adverse events, including somnolence. ${ }^{63}$

Despite the small number of studies, the best results seem to be those obtained with cetirizine, levocetirizine and desloratadine, and regarding dosage increase, there were mixed results with rupatadine and one study with fexofenadine failed to show greater improvement with higher doses. ${ }^{63}$

Overall, studies comparing various secondgeneration anti-H1 drugs in the treatment of CU, observed no significant difference regarding symptom control, quality-of-life and safety profile, and all of them are designated as first-line agents in the treatment of CU. 2,58 Chart 5 summarizes the recommendations for the treatment of urticaria, according to the " $4^{\text {th }}$ Consensus Meeting, Urticaria 2012" held in Berlin. An ample variety of H1-antihistamines available on the market, their dosage and recommended doses can be seen on chart 6 . 
A recent review performed by Fedorowiczet $a l^{64}$ for the "Cochrane Skin Group Specialized Register" concluded that the presence of few studies and small case series in the literature regarding the use of anti$\mathrm{H} 2$ (cimetidine and ranitidine) in the treatment of urticaria, preclude any conclusion on their effectiveness in treating the disease.

\section{Other pharmacological interventions in chronic urticaria (third-line agents)}

While anti-histaminic treatments with highdose second-generation anti-H1 (up to four times the recommended doses) can control the symptoms in most patients, alternative treatments may be required for the remaining unresponsive population. ${ }^{2}$ Since the intensity of chronic urticaria fluctuates, and spontaneous remission may occur in $50 \%$ of patients within 6 months of diagnosis, it is advisable to re-evaluate the need for continued treatment or alternative therapies every 3 to six months, although in our opinion, patients should be assessed at interval periods no longer than two months. ${ }^{2}$ There are numerous studies on alternative drugs for the treatment of chronic urticaria, either in combination with H1-antihistamines or as monotherapy, however with low levels of scientific evidence. ${ }^{2}$ Examples for this strategy include: ketotifen, montelukast, warfarin, nifedipine, tranexamic acid, colchicine, dapsone, sulfasalazine, methotrexate, plasmapheresis, intravenous immunoglobulin, hydroxychloroquine, biological agents, danazol / stanozolol and cyclophosphamide, among others. ${ }^{4}$ Even with low levels of scientific evidence, many of these drugs are used in antihistamineresistant patients with chronic urticaria, therefore we will discuss them further along.

\section{Cyclosporine}

Most studies on cyclosporine used 5 $\mathrm{mg} / \mathrm{kg} /$ day doses for periods ranging from 8-16 weeks with good results, varying from $64 \%$ to $95 \%$ approximately. Some studies used smaller doses (2 to $5 \mathrm{mg} / \mathrm{kg} /$ day). ${ }^{65-69}$ At these doses, side effects occur less frequently than at higher ones. In these cases, particularly, there have been reports on infections, hypertension, nephrotoxicity and increased malignancy. ${ }^{70,71}$ Other less severe side effects include hirsutism, headache, nausea, paresthesias, abdominal pain and hypertension. For this reason, it is necessary to monitor blood pressure, renal function and cyclosporine levels and even glycemia and lipidemia. ${ }^{70,71}$

\section{Methotrexate}

This drug has anti-inflammatory and immunosuppressive activities, although much of its mechanisms of action are unknown. It is known that, methotrexate increases adenosine levels, inducing the apoptosis of CD4 lymphocytes and inhibiting neutrophil chemotaxis. It has been used in doses of 10 to $15 \mathrm{mg}$ per week in cases that were resistant to antihistamines and systemic corticosteroids, with results

CHART 5: Management of urticaria: recommendation guide proposed by the "4th International Meeting on Urticaria Consensus" in 2012

\begin{tabular}{|c|c|}
\hline $\begin{array}{l}\text { Terminology and } \\
\text { classification }\end{array}$ & $\begin{array}{l}\text { Chronic urticaria may occur as "chronic spontaneous urticaria" or "inducible chronic urticaria". The inducible } \\
\text { group includes physical, cholinergic, contact and aquagenic urticarias; the term "idiopathic" chronic urticaria } \\
\text { should be avoided. }\end{array}$ \\
\hline $\begin{array}{l}\text { Differential } \\
\text { diagnoses }\end{array}$ & $\begin{array}{l}\text { Differential diagnoses should include bradykinin-related angioedema (hereditary angioedema and angioedema } \\
\text { secondary to angiotensin conversion inhibitors) and urticarial syndromes associated with interleukin-1 (auto- } \\
\text { inflammatory syndromes or diseases, urticaria-vasculitis) }\end{array}$ \\
\hline $\begin{array}{l}\text { Determination of } \\
\text { disease activity }\end{array}$ & $\begin{array}{l}\text { a. New methods and tools are available. } \\
\text { b. Disease activity: UAS (urticaria activity score), AAS (angioedema activity score), triggering threshold of induci- } \\
\text { ble urticaria. } \\
\text { C. Quality of life: CU-Q2oL (chronic urticaria quality of life survey chronic urticaria), AE-QoL (angioedema quali- } \\
\text { ty of life survey - quality of life questionnaire for patients with angioedema) }\end{array}$ \\
\hline Diagnosis & $\begin{array}{l}\text { a. In spontaneous chronic urticaria there are two steps to the diagnosis: } \\
\text { - Routine diagnosis (exclusion of serious underlying diseases in all patients): ESR or C-reactive protein, complete } \\
\text { blood count, suspend the use of non-steroidal anti-inflammatory drugs or substitute them. } \\
\text { - Complementary diagnosis (to identify and treat possible causes in patients with persistent disease and/or severe } \\
\text { spontaneous urticaria): based overall on the patient's medical history, detection of autoreactivity, intolerance, and } \\
\text { infection. } \\
\text { b. In inducible chronic urticaria, the diagnosis is limited (usually) to determining the triggering factor and the } \\
\text { tolerance threshold to stimuli. }\end{array}$ \\
\hline Treatment & $\begin{array}{l}\text { Treatment is indicated in three steps: } \\
\text { Step 1: non-sedating, second-generation antihistamines } \\
\text { Step 2: doses up to four times those recommended on the label of non-sedating, second-generation antihistamines } \\
\text { Step 3: Omalizumab, cyclosporine A, montelukast. }\end{array}$ \\
\hline
\end{tabular}

Adapted from Zuberbier Tet $\mathrm{al}^{2}$ 
CHART 6: Absorption, doses and metabolism of $\mathrm{H1}$ antihistamines ( : available in Brazil)

\begin{tabular}{|c|c|c|c|c|c|c|c|c|}
\hline Generation & Drugs & $\begin{array}{l}\text { Dose for chil- } \\
\text { dren (day) }\end{array}$ & Dose for adults (day) & $\mathrm{T}$ max* & $\begin{array}{l}\text { Time to } \\
\text { action } \\
\text { (hours)** }^{*}\end{array}$ & $\begin{array}{l}\text { Hepatic } \\
\text { metabolism }\end{array}$ & $\begin{array}{l}\text { Drug } \\
\text { interactions }\end{array}$ & $\begin{array}{l}\text { Dose } \\
\text { adjust }\end{array}$ \\
\hline \multirow[t]{6}{*}{ 1st } & $\begin{array}{l}\text { Chlorpheniramine } \\
\text { (Dex })\end{array}$ & $0.15 \mathrm{mg} / \mathrm{kg} /$ day & $2-8 \mathrm{mg} /$ day. $\div 3$ doses & $2.8 \pm 0.8$ & 3 & Yes & Likely & ND \\
\hline & Clemastine & $0.5 \mathrm{ml} / \mathrm{kg} /$ day & $2 \mathrm{mg}$ & nd & 2 & Yes & Likely & ND \\
\hline & Cyproheptadine & $0.125 \mathrm{mg} / \mathrm{kg} /$ day & $2-8 \mathrm{mg}$ & nd & ND & Yes & Likely & LF \\
\hline & Diphenhydramine & $\begin{array}{l}5 \mathrm{mg} / \mathrm{Kg} \div 3-4 \\
\text { times/day }\end{array}$ & 50 to $400 \mathrm{mg}$ & $1.7 \pm 1.0$ & 2 & Yes & Likely & LF \\
\hline & Doxepin & Not used & $10-100 \mathrm{mg}$ & 2 & nd & Yes & Likely & LF \\
\hline & Hydroxyzine & $1-2 \mathrm{mg} / \mathrm{kg} /$ day & $10-200 \mathrm{mg}$ & $2.1 \pm 0.4$ & 2 & Yes & Likely & LF \\
\hline \multirow[t]{11}{*}{ 2nd } & Acrivastine & Unavailable & Unavailable & $1.4 \pm 0.4$ & 1 & $<50 \%$ & Unlikely & ND \\
\hline & Bilastine & $\begin{array}{l}\text { Unavailable (only> } \\
12 \text { years old) }\end{array}$ & $20 \mathrm{mg}$ & $1.0-1.5$ & 1 & No & & \\
\hline & Ketotifen & $0.05 \mathrm{mg} / \mathrm{kg} /$ day & $1-2 \mathrm{mg}$ & $3.6 \pm 1.6$ & ND & Yes (?) & ND & LF e KF \\
\hline & Cetirizine & $\begin{array}{l}2-6 \text { years, } 2.5 \\
\text { mg.6-12 years, } \\
5 \mathrm{mg} ; 2 \mathrm{x} / \text { day }\end{array}$ & $10 \mathrm{mg}$ & $1.0 \pm 0.5$ & 1 & $<40 \%$ & Unlikely & IH e IR \\
\hline & $\begin{array}{l}\text { Loratadine / } \\
\text { Descarboethoxy- } \\
\text { loratadine }\end{array}$ & $\begin{array}{l}2-6 \text { years, } 2.5 \mathrm{mg} \text {. } \\
6-12 \text { years, } \\
5 \mathrm{mg} ; 1 \mathrm{x} / \text { day }\end{array}$ & $10 \mathrm{mg}$ & $\begin{array}{l}1.2 \pm 0.3 \\
1.5 \pm 0.7\end{array}$ & 2 & Yes & Very unlikely & LF e KF \\
\hline & $\begin{array}{l}\text { Ebastine / } \\
\text { Carebastine }\end{array}$ & $\begin{array}{l}2-6 \text { years, } 2.5 \mathrm{mg} \text {. } \\
6-12 \text { years, } \\
5 \mathrm{mg} ; 1 \mathrm{x} / \text { day }\end{array}$ & $60 / 180 \mathrm{mg}$ & $2.6 \pm 5.7$ & 2 & Yes & Likely & LF e KF \\
\hline & Fexofenadine & $\begin{array}{l}>12 \text { years- } 60 \mathrm{mg} \\
2 \mathrm{x} / \text { day }\end{array}$ & $\begin{array}{l}\text { ( } 6 \text { monthsto } 2 \text { years: } \\
2.5 \mathrm{ml} \text { q. } 12 \text { hours) } \\
\text { ( } 2 \text { to } 11 \text { years: } 5 \mathrm{mg} \text { q. } \\
\text { to hours) }\end{array}$ & 2.6 & 2 & $\begin{array}{l}<8 \% \\
\text { Yes }\end{array}$ & $\begin{array}{l}\text { Yes (P-gly- } \\
\text { coprotein) }\end{array}$ & KF \\
\hline & Mizolastine & Unavailable & Unavailable & 1.5 & 1 & Yes & Likely & ND \\
\hline & Levocetirizine & $\begin{array}{l}\varnothing 2 \text { to } 6 \text { years: } 5 \\
\text { dropsq } 12 \text { hour- } \\
\text { sor }(0.25 \\
\text { mg/kg/ day) } \\
\varnothing 6 \text { anos: } 5 \mathrm{mg}\end{array}$ & $5 \mathrm{mg}$ & $0.8 \pm 0.5$ & 1 & $<15 \%$ & Unlikely & LF e KF \\
\hline & Desloratadine & $\begin{array}{l}\text { 6months-1year, } \\
1 \mathrm{mg} ; 1-6 \text { years, } \\
1.25 \mathrm{mg} .6-12 \\
\text { years, } 2.5 \mathrm{mg} ; 1 \mathrm{x} \\
\text { / day }\end{array}$ & $5 \mathrm{mg}$ & $1-3$ & 2 & Yes & Unlikely & LF e KF \\
\hline & Rupatadine & Unavailable & $10 \mathrm{mg}$ & 0.75 & 2 & Yes & Unlikely & \\
\hline
\end{tabular}

Legend: LF, liver failure; KF, kidney failure; ND, not defined.

achieved after 3 to 6 weeks of treatment. ${ }^{72,73}$ It is considered as a corticosteroid-sparing alternative. Gastrointestinal side effects, stomatitis, headache, fatigue, and hematological alterations may occur at low doses. ${ }^{72,73}$ Since there is the risk of hepatotoxicity and myelosuppression, laboratory surveillance is mandatory, especially of hepatic function. ${ }^{72,73}$

\section{Cyclophosphamide}

Prescribed usually in cases of extreme treatment resistance, it has been used orally at $100 \mathrm{mg}$ doses (equivalent to $1.5 \mathrm{mg} / \mathrm{kg}$ for 5 days, every week) associated with $600 \mathrm{mg} /$ day acetylcysteine to reduce bladder toxicity, with good results. ${ }^{74}$ It should be used sparingly, due to its many potential adverse events. ${ }^{74}$ 


\section{Biologic agents}

a. Intravenous immunoglobulin

It has immunomodulatory activities, including complement and cell adhesion modulation and acts at the level of cytokines and autoantibodies. This drug has been used with good results in $\mathrm{CU}$, at a dose of 0.4 $\mathrm{mg} / \mathrm{kg} /$ day for 5 consecutive days, or in other schemes, both intravenously and subcutaneously. ${ }^{75-77}$ Anaphylactoid reactions, aseptic meningitis and renal failure are reported as rare adverse events and despite being relatively safe, this is a very high-cost treatment.

\section{b. Omalizumab}

This is an anti-IgE monoclonal antibody approved for the treatment of moderate to severe asthma. It decreases free $\operatorname{IgE}$ and inhibits the expression of high affinity $\operatorname{IgE}$ receptors on mast cells and basophils. Applied subcutaneously, it was one of the first biopharmaceuticals on the market indicated to treat severe allergic asthma. When treating CU, one must take in consideration the presence of $\operatorname{IgE}$ autoantibodies. ${ }^{78,79}$ Good results have been reported in idiopathic and cholinergic $\mathrm{CU}$, urticaria secondary to sun or cold exposure, dermographism and angioedema. ${ }^{78,79}$

A randomized multicenter, double-blinded study evaluated 90 patients with chronic spontaneous urticaria unresponsive to antihistamines, aged 12-75 years, and good control of the disease was achieved with one dose of omalizumab. ${ }^{80}$ The improvement obtained with the medication versus placebo was statistically significant at 300 and $600 \mathrm{mg}$ doses, but not at $75 \mathrm{mg}$, complete resolution of urticaria was achieved in the first two weeks in $36 \%$ of patients in the $300 \mathrm{mg}$ group, $28.6 \%$ in the $600 \mathrm{mg}$ and $4.4 \%$ in the $75 \mathrm{mg}$ and $0 \%$ in the placebo group. ${ }^{80}$

Recently, a randomized multicenter study with 323 patients treated every 4 weeks observed, at week 16 , a $44 \%$ improvement in the $300 \mathrm{mg}$ group, $22 \%$ at $150 \mathrm{mg}$, $16 \%$ in the $75 \mathrm{mg}$ group and $5 \%$ in the placebo group. ${ }^{81}$

Therefore, the use of omalizumab at $300 \mathrm{mg}$ or $600 \mathrm{mg}$ doses seems to be a rapid and effective treatment for patients with CU who are persistently symptomatic despite the use of anti-H1 medications. ${ }^{81,82}$

\section{c. Anti-CD20 drugs (Rituximab and other)}

It is a chimeric monoclonal antibody against CD20 protein, which is expressed mainly on B cells (lymphocytes). ${ }^{82}$ Rituximab destroys B-lymphocytes and decreases the production of autoantibodies. In three case reports, the drug was effective in two patients with $\mathrm{H1}$-antihistamine resistant $\mathrm{CU}$ and in another case it was ineffective. ${ }^{83-85}$

\section{d. Anti-TNF-alpha agents}

Wilson et $a l^{86}$ treated 6 patients with $\mathrm{CU}$, who had unsuccessfully received a combination of $\mathrm{H1}$ antihistamines and immunosuppressants, with different anti-TNF agents (4 with etanercept, 1 infliximab and 1 adalimumab) based on previous studies that had shown elevated serum and cutaneous TNF $\alpha$ in patients with CU compared to controls. ${ }^{87.88}$ The authors reported improvement on the urticaria, with length of remission varying from months to years, and three patients continuing in long-lasting remissions even after all medications were withdrawn. ${ }^{86}$

\section{Corticosteroids}

Corticosteroids are known to be effective in the treatment of $\mathrm{CU}$ in patients who are unresponsive to anti-H1 medications ${ }^{82}$ Nonetheless, controlled studies on the subject are still lacking. Clinical effects may be evident at $25 \mathrm{mg}$ doses in the early days of treatment, however, given the potential adverse events associated with the chronic use of corticosteroids (diabetes mellitus, hypertension, osteoporosis and gastrointestinal bleeding), oral corticosteroids should be used for short periods of time (3-7 days per month) and at the smallest effective dose. ${ }^{2,82}$

\section{Drugs with anti-inflammatory effects}

These medications are generally safe and affordable to the majority of the population, have still limited evidence of effectiveness in the literature, but can be used in the treatment of CU before more expensive or toxic drugs are considered. ${ }^{82}$

\section{a. Hydroxychloroquine}

Reeves et al ${ }^{89}$ studied 18 patients with $\mathrm{CU}$ who were treated with hydroxychloroquine for 12 weeks. The treatment significantly improved the quality of life of patients, although the levels of urticaria activity suffered little influence. This drug is relatively safe, though it can cause retinopathy usually after 5 years of continuous use..$^{82}$

\section{b. Colchicine}

There are two studies published in the indexed literature, a prospective one by Criado $e t a l^{55}$ and a retrospective analysis by Pho et $\mathrm{al}^{90}$, evaluating the use of colchicine in the treatment of CU. The drug acts by precluding the formation of the apparatus that extrudes granules from mast cells and basophils. Both studies found partial or complete response in at least half the patients. Adverse events are bearable, including diarrhea, leukopenia, and hematuria; furthermore it is a low-cost medication. Colchicine should not be used in pregnant women.

c. Dapsone

Dapsone has been reported to be effective in the 
treatment of CU/angioedema at doses of 25 to $50 \mathrm{mg}$ per day. ${ }^{5,55,82,91}$ In a study, in association with desloratadine and as monotherapy, it showed higher rates of remission, although urticaria activity scores were not reduced. ${ }^{22}$ According to Noda et al, dapsone's antiinflammatory activity occurs by inhibiting the chemotactic migration of neutrophils, protecting cells from neutrophil and eosinophil-mediated damage, reducing the release of prostaglandins and leukotrienes and reducing the integrin-mediated neutrophil adherence, which inhibits the migration of these cells into the extravascular compartment. ${ }^{91}$ Although generally well tolerated, dapsone can induce dose-dependent anemia and less frequently peripheral neuropathy, exanthema, DRESS syndrome, gastrointestinal symptoms, hepatotoxicity and methemoglobinemia. Monitoring serum levels of glucose-6-phosphate dehydrogenase (G6PD) is necessary, due to the risk of severe hemolysis in patients lacking this enzyme. ${ }^{82}$

\section{d. Sulfasalazine}

The recommended dose is $2 \mathrm{~g}$, p.o daily, with results usually seen within a month. ${ }^{82}$ Adverse events such as nausea, dyspepsia, headache, proteinuria, hepatotoxicity and hematologic abnormalities have been reported..$^{82}$

\section{Leukotriene receptor antagonist (Montelukast)}

Montelukast is used at $10 \mathrm{mg}$ per day in adults, as an adjuvant drug to the anti-histaminic treatment, with excellent safety profile. ${ }^{55,82}$ Leukotrienes C4, D4 and $\mathrm{E} 4$ play an important role in the process of allergic inflammation, warranting this drug as an adjunct in the treatment of CU. Khan \& Lynch ${ }^{93}$ achieved CU control in $48 \%$ of 25 patients treated with montelukast associated to anti-H1 and anti-H2, 11 had no improvement and in two patients the urticaria worsened after the drug was introduced. Adverse events included upper respiratory tract symptoms, diarrhea, nausea, vomiting, exanthema, elevated transaminases and exceptionally, psychiatric disorders. ${ }^{93}$

\section{Anticoagulants}

Frequently, patients with CU show an increase in plasma markers of thrombin generation and fibrinolysis during periods of disease exacerbation, perhaps as a consequence of tissue factor expression on the plasma membrane of activated eosinophils. ${ }^{82,94}$ The activation of coagulation and fibrinolysis decreases as the disease enters remission. ${ }^{82}$ The exact role of this phenomenon (activation of coagulation and fibrinolysis) acting as the centerpiece of the disease's pathophysiology or epiphenomenon acting as an amplifier of inflammation, is not yet elucidated. According to Asero et $a l^{82}$ it seems reasonable to use anticoagulant or antifibrinolytic agents in patients with $\mathrm{CU}$, since the disease's activity runs parallel to this phenomenon. Reports on the use of oral anticoagulation, warfarin (keeping INR over 2) and also heparin have been published for the last decade. ${ }^{95-}$ ${ }^{98}$ However, the use of these drugs is still not routinely recommended in the treatment of $\mathrm{CU} .{ }^{82}$

\section{Levothyroxine}

The association between thyroid autoimmunity and $\mathrm{CU}$ is well established. Karaayvazet $a l^{99}$ conducted a study with 60 patients with UC, divided into two groups matched for sex and age, using ketotifen or levocetirizine. The group using ketotifen achieved symptom relief while taking the medication, but relapsed after drug withdrawal. Eighteen patients in the group using levothyroxine achieved complete remission and 3 had partial improvements; furthermore, symptoms did not recur in those with complete response. Treatment with levothyroxine takes at least 10 days to demonstrate effect; $0.1 \mathrm{mg} / \mathrm{kg} /$ day for four weeks is usually appropriate and does not cause alterations in thyroid function..$^{99}$ It is advisable to approach these cases in conjunction with an endocrinologist, especially in situations where no control of chronic urticaria associated to thyroid autoimmunity was obtained with other pharmacological interventions and provided that there are no contraindications to thyroid hormone replacement therapy ${ }^{99}$ It is hypothesized that patients with autoimmune thyroiditis have autoantibodies against thyroid proteins (antithyroglobulin and antiperoxidase), which induce inflammation and cytokine release that will subsequently bind to C4, activate the complement system and stimulate the release of histamine by basophils and mast cells. ${ }^{100}$ Thus, antithyroid and anti-FceRI $\alpha$ antibodies activate the complement in a synergic manner, increasing the release of vasoactive amines, leading to urticaria.

\section{Therapeutic strategies in clinical practice}

In our understanding, the treatment of chronic urticaria should be customized according to the patients' lifestyles (profession, social interactions and recreational activities), their socioeconomic level and understanding of disease and treatment. A basic principle is to avoid known aggravating or triggering agents, such as alcohol and indiscriminate use of COX inhibitors and nonsteroidal anti-inflammatory drugs. Each therapeutic intervention cannot be assessed as to its effectiveness before 2 to 4 weeks, at the earliest. If disease control is not achieved with a certain drug, as long as there is no contraindication for an association, it should be maintained at least until the illness is controlled.

Patients with CU tend to develop psychologi$\mathrm{cal} /$ psychiatric problems, some even preceding the initial event of urticaria, such as post-traumatic stress disorder, alexithymia (marked difficulty in verbaliz- 
ing emotions, describing feelings or bodily sensations), anxiety (particularly phobias) and depression, which may affect up to $48 \%$ of patients with spontaneous CU..$^{101-103}$ Thus, psychological and/or psychiatric support, beside positive attitudes from the health care team can always be helpful to the treatment.

The quality-of-life of patients with CU is greatly affected, as patients suffer with pruritus, wheals and present fatigue caused by sleep disorders and adverse events of medications. ${ }^{104}$ The disease affects many realms of the patient's life, having also an economic impact for the patient and the health system. ${ }^{104}$ In tertiary referral centers, the impact in quality of life for these patients is comparable to that experienced by older subjects with severe ischemic heart disease and overall, on various dimensions, to the impact suffered by patients with psoriasis and atopic dermatitis. ${ }^{104}$

So, face to the reality of medical practice in Brazil, we adopted a strategy of sequential treatment (in steps), ranging from the use of anti-H1 as standard initial drugs, to second-line agents (leukotrienes and corticosteroids in short courses), third-line medications (omalizumab, cyclosporine, methotrexate; antiinflammatory drugs, such as dapsone, hydroxychloroquine and colchicine) and fourth-line drugs (immunosuppressants that are more toxic), considering that in most cases, progression to the next level of therapy also implies increase in direct or indirect costs, as well as greater risks of adverse events (Figure 2). ${ }^{82}$

\section{Chronic urticaria: severity markers and disease prognosis}

Rabelo-Filardiet a ${ }^{105}$ in a systematic review of 34 studies published on spontaneous chronic urticaria, concluded that the clinical severity of CU can forecast disease duration, and laboratory parameters such as elevation of serum levels of fragments $1+2$ prothrombin, d-dimer and C-reactive protein (CRP) may reflect the gravity of the disease, and perhaps its resistance to conventional treatment. Patients with more severe symptoms may have more persistent disease courses. ${ }^{106}$ Spontaneous remissions occur in $30-50 \%$ of patients within a year of disease evolution, and another $20 \%$ within 5 years. ${ }^{106}$ About $20 \%$ of patients with CU remain ill after five years of evolution. ${ }^{106}$ Nearly half of patients with CU lasting six months, will probably still have the disease 10 years later. ${ }^{106}$

A Korean study with 131 patients with CU evaluated the presence of signs of metabolic syndrome, disease activity score and serum markers for inflammatory activity. ${ }^{107}$ Thirty-nine patients $(28.9 \%)$ had metabolic syndrome (MetS) compared to $17.8 \%$ of subjects in the matched control group $(\mathrm{P}=0.001)$. Patients with CU and metabolic syndrome were older, had higher mean scores of disease activity, higher levels of serum eosinophil cationic protein (ECP), TNFa and complement system factors, besides higher frequency of negative TCSA when compared to patients with CU without MetS. Logistic regression showed that an urticaria activity score $\geq 13(\mathrm{p}=0.025)$ and the presence of MetS $(p=0.036)$ were independent predictors of a likely difficult-to-treat CU. ${ }^{107}$ Therefore, both $\mathrm{CU}$ and MetS may share low-grade chronic inflammation, involving $\mathrm{TNF} \alpha, \mathrm{ECP}$ and $\mathrm{C} 3$, which may be mutually triggering or exacerbating the disease. ${ }^{107}$ Future studies will better elucidate subsequent disorders in patients with $\mathrm{CU}$, since the disease may course with coexisting MetS, activation of coagulation/fibrinolysis and chronic inflammation, which may represent potential cardiovascular diseases and diabetes mellitus during the life of these patients.

\section{CONCLUSIONS}

- CU is currently classified as spontaneous or induced by physical stimuli. Convention determined that the term "idiopathic" should be avoided;

- Studies with larger samples should be conducted in the future, to assess the value of screening and treatment of infectious and parasitic agents in the course of CU, especially in endemic areas;

- The presence of autoreactivity in patients with spontaneous CU can be demonstrated in $50 \%$ of cases, in a simple manner by the autologous serum skin test;

- The vast majority of CUs are not IgE-mediated allergic diseases.

- The diagnosis of autoimmune CU should be based on strict criteria established by the European consensus;

- The link between inflammation and coagulation, boosting the mediators release cascade was demonstrated in a group of patients with $\mathrm{CU}$ and high levels of eosinophilic activation;

- First-line treatment of CU in the first decade of this century is based on second-generation antihistamines, however in some patients it is necessary to associate anti-inflammatory or immunosuppressive drugs, besides the promising use of immunobiological agents such as omalizumab;

- Similar to some cases of psoriasis, spontaneous CU can have a major impact on patients' qualityof-life, and also in the various realms of the psyche. Further studies will confirm or deny, the progressive course of metabolic syndrome and cardiovascular complications among patients with long lasting spontaneous CU.D 


\section{REFERENCES}

1. Cousin F, Philips K, Favier B, Bienvenu J, Nicolas JF. Drug-induced urticaria. Eur J Dermatol. 2001;11:181-7.

2. Zuberbier T, Aberer W, Asero R, Bindslev-Jensen C, Brzoza Z, Canonica GW, et al. The EAACI/GA(2) LEN/EDF/WAO Guideline for the definition, classification, diagnosis, and management ofurticaria: the 2013 revision and update. Allergy. 2014;69:868-87.

3. Hizal $M$, Tüzün $B$, Wolf $R$, Tüzün $Y$. The relationship between Helicobacter pylori IgG antibody and autologous serum test in chronic urticaria. Int J Dermatol. 2000;39:443-5.

4. Federman DG, Kirsner RS, Moriarty JP, Concato J. The effect of antibiotic therapy for patients infected with Helicobacter pylori who have chronic urticaria. J Am Acad Dermatol. 2003;49:861-4.

5. Burova KP, Mallet Al, Greaves MW. Is Helicobacter pylori a cause of urticaria? Br J Dermatol. 1999;51:42.

6. Greaves MW. Chronic idiopathic urticaria and $\mathrm{H}$ pylori: not directly causative but could there be a link? ACl Int. 2001;13:23-26.

7. Tharp MD, Thirlby R, Sullivan TJ. Gastrin induces histamine release from human cutaneous mast cells. J Allergy Clinlmmunol. 1984;74:159-65

8. Lessof MH, Gant V, Hinuma K, Murphy GM, Dowling RH. Recurrent urticaria and reduced diamine oxidase activity. Clin Exp Allergy. 1990;20:373-6.

9. Maintz L, Novak N. Histamine and histamine intolerance. Am J Clin Nutr. 2007;85:1185-96.

10. Asero R. Multiple intolerance to food additives. J Allergy Clinlmmunol. 2002;110:531-2

11. Simon RA. Additive-induced urticaria: experience with monosodium glutamate (MSG). J Nutr. 2000;130:1063S-6S.

12. Di Lorenzo G, Pacor ML, Mansueto P, Martinelli N, Esposito-Pellitteri M, Lo Bianco C, et al. Food-additive-induced urticaria: a survey of 838 patients with recurrent chronic idiopathic urticaria. Int Arch Allergy Immunol. 2005;138:235-42.

13. Goga D, Vaillant L, Pandraud L, Mateu J, Ballon G, Beutter P. The elimination of dental and sinusal infectious foci in dermatologic pathology. A double-blind study in 27 cases confined to chronic urticaria. Rev Stomatol Chir Maxillofac. 1988;89:273-5.

14. Vaida GA, Goldman MA, Bloch KJ. Testing for hepatitis B virus in patients with chronic urticaria and angioedema. J Allergy Clin Immunol. 1983;72:193-8.

15. Siddique N, Pereira BN, Hasan Arshad S. Hepatitis C and urticaria: cause and effect? Allergy. 2004;59:668.

16. Nenoff P, Domula E, Willing U, Herrmann J.[Giardia lamblia--cause of urticaria and pruritus or accidental association?]. Hautarzt. 2006;57:518-20, 521-2.

17. Demirci M, Yildirim M, Aridogan BC, Baysal V, Korkmaz M. Tissue parasites in patients with chronic urticaria. J Dermatol. 2003;30:777-81.

18. Ismail MA, Khalafallah 0 . Toxocaracanis and chronic urticaria in Egyptian patients J Egypt Soc Parasitol. 2005;35:833-40.

19. Gulalp B, Koseoglu Z, Toprak N, Satar S, Sebe A, GokelY, et al. Ruptured hydatid cyst following minimal trauma and few signs on presentation. Neth $\mathrm{J}$ Med. 2007;65:117-8.

20. Pattison DA, Speare R. Strongyloidiasis in personnel of the Regional Assistance Mission to Solomon Islands (RAMSI). Med J Aust. 2008;189:203-6.

21. Marseglia GL, Marseglia A, Licari A, Castellazzi AM, Ciprandi G. Chronic urticaria caused by Hymenoleptis nana in an adopted girl. Allergy. 2007;62:821-2.

22. Zuel-Fakkar NM, Abdel Hameed DM, Hassanin OM. Study of Blastocystishominis isolates in urticaria: a case-control study. Clin Exp Dermatol. 2011;36:908-10.

23. Nenoff $P$, Domula E, Willing U, Herrmann J. [Giardia lamblia--cause of urticaria and pruritus or accidental association?]. Hautarzt. 2006;57:518-20, 521-2.

24. Kaji K, Yoshiji H, Yoshikawa M, Yamazaki M, Ikenaka Y, Noguchi R, et al Eosinophilic cholecystitis along with pericarditis caused by Ascarislumbricoides: a case report. World J Gastroenterol. 2007;13:3760-2.

25. Criado PR, Belda Junior W, Criado RF, Vasconcelos e Silva R, Vasconcellos C. Bedbugs (Cimicidae infestation): the worldwide renaissance of an old partner of human kind. Braz J Infect Dis. 2011;15:74-80.

26. Spiewak R, Lundberg M, Johansson G, Buczek A. Allergy to pigeon tick (Argasreflexus) in Upper Silesia, Poland. Ann Agric Environ Med. 2006;13:107-12.

27. Armentia A, Martin-Gil FJ, Pascual C, Martín-Esteban M, Callejo A, Martínez C. Anisakis simplex allergy after eating chicken meat. J Investig Allergol Clin Immunol. 2006;16:258-63.

28. Daschner A, De Frutos C, Valls A, Vega F. Anisakis simplex sensitization-associated urticaria: short-lived immediate type or prolonged acute urticaria. Arch Dermatol Res. 2010;302:625-9.

29. Leznoff A, Josse RG, Denburg J, Dolovich J. Association of chronic urticaria and angioedema with thyroid autoimmunity. Arch Dermatol. 1983;119:636-40.

30. Leznoff A, Sussman GL. Syndrome of idiopathic urticaria and angioedema with thyroid autoimmunity: a study of 90 patients. J Allergy Clin Immunol. 1989;84:66-71.
31. Zauli D, Grassi A, Ballardini G, Contestabile S, Zucchini S, Bianchi FB. Thyroid autoimmunity in chronic idiopathic urticaria. Am J Clin Dermatol. 2002;3:525-8.

32. Turktas I, Gokcora N, Demirsoy S, Cakir N, Onal E. The association of chronic urticaria and angioedema with autoimmune thyroiditis. Int J Dermatol. 1997;36:187-90.

33. Rottem M. Chronic urticaria and autoimmune thyroid disease: is there a link? Autoimmun Rev. 2003;2:69-72.

34. Konstantinou GN, Asero R, Maurer M, Sabroe RA, Schmid-Grendelmeier P, Grattan CE. EAACI/GA(2)LEN task force consensus report: the autologous serum skin test in urticaria. Allergy. 2009;64:1256-68.

35. Tedeschi A, Cottini M, Asero R. Simultaneous occurrence of chronic autoimmune urticaria and non-allergic asthma: a common mechanism? Eur Ann Allergy Clin Immunol. 2009;41:56-9.

36. Confino-Cohen R, Chodick G, Shalev V, Leshno M, Kimhi 0, Goldberg A. Chronic urticaria and autoimmunity: associations found in a large population study. J Allergy Clin Immunol. 2012;129:1307-13.

37. Cugno M, Marzano AV, Asero R, Tedeschi A. Activation of blood coagulation in chronic urticaria: pathophysiological and clinical implications. Intern Emerg Med. 2010;5:97-101.

38. Asero R, Tedeschi A, Riboldi P, Griffini S, Bonanni E, Cugno M.Severe chronic urticaria is associated with elevated plasma levels of D-dimer. Allergy. 2008;63:176-80

39. Takahagi S, Mihara S, Iwamoto K, Morioke S, Okabe T, Kameyoshi Y, et al. Coagulation/fibrinolysis and inflammation markers are associated with disease activity in patients with chronic urticaria. Allergy. 2010;65:649-56.

40. Konstantinou GN, Asero R, Ferrer M, Knol EF, Maurer M, Raap U, et al. EAACI taskforce position paper: evidence for autoimmune urticaria and proposal for defining diagnostic criteria. Allergy. 2013;68:27-36.

41. Augey F, Gunera-Saad N, Bensaid B, Nosbaum A, Berard F, Nicolas JF. Chronic spontaneous urticaria is not an allergic disease. Eur J Dermatol. 2011;21:349-53.

42. Caliskaner Z, Ozturk S, Turan M, Karaayvaz M.Skin Test positivity to aeroallergens in the patients with chronic urticaria without respiratory disease. J Investig Allergol Clin Immunol. 2004;14:50-4

43. Kozel MM, Mekkes JR, Bossuyt PM, Bos JD. Natural course of physical and chronic urticaria and angioedema in 220 patients. J Am Acad Dermatol. 2001;45:387-91.

44. Młynek A, Zalewska-Janowska A, Martus P, Staubach P, Zuberbier T, Maurer M. How to assess disease activity in patients with chronic urticaria? Allergy. 2008:63:777-80.

45. Grattan CEH. The urticaria spectrum: recognition of clinical patterns can help management. Clin Exp Dermatol. 2004;29:217-21.

46. Malmros H. Autoserumtest. Nordisk Med 1946;29:150-1.

47. Sabroe RA, Greaves MW. Chronic idiopathic urticaria with functional autoantibodies: 12 years on. Br J Dermatol. 2006;154:813-9.

48. Yıldız H, Karabudak O, Doğan B, Harmanyeri Y. Evaluation of autologous plasma skin test in patients with chronic idiopathic urticaria. $\mathrm{Br} J$ Dermatol. 2011;165:1205-9.

49. Asero R, Tedeschi A, Riboldi P, Cugno M. Plasma of patients with chronic urticaria shows signs of thrombin generation, and its intradermal injection causes whealand-flare reaction much more frequently than frequently than autologous serum. J Allergy Clin Immunol. 2006;117:1113-7.

50. Metz M, Giménez-Arnau A, Borzova E, Grattan CE, Magerl M, Maurer M. Frequency and clinical implications of skin autoreactivity to serum versus plasma in patients with chronic urticaria. J Allergy Clin Immunol. 2009;123:705-6.

51. Yıldız H, Karabudak O, Doğan B, HarmanyeriY.Evaluation of autologous plasma skin test in patients with chronic idiopathic urticaria.Br J Dermatol. 2011;165:1205-9.

52. Criado PR, Criado RFJ, Maruta CW, Martins JEC, Rivitti EA. Urticaria. An Bras Dermatol 2005;80;613-30

53. Criado PR, Criado RFJ, Maruta CW, Machado CDA. Histamine, histamine receptors and antihistamines: new concepts. An Bras Dermatol. 2010;85:195-210.

54. Pires JS, de Ue APF, Furlani EJ, de Souza PK, Rotta 0. Dapsone as an alternative to the treatment of chronic urticaria non-responsive to antihistamines. An Bras Dermatol. 2008:83:413-8.

55. Criado RF, Criado PR, Martins JE, Valente NY, Michalany NS, Vasconcellos C. Urticaria unresponsive to antihistaminic treatment: an open study of therapeutic options based on histopathologic features. J Dermatolog Treat. 2008;19:92-6.

56. Jáuregui I, Ferrer M, Montoro J, Dávila I, Bartra J, del Cuvillo $\mathrm{A}$, et al Antihistamines in the treatment of chronic urticaria. J Investig Allergol Clin Immunol. 2007;17:41-52.

57. Kalivas J, Breneman D, Tharp M, Bruce S, Bigby M. Urticaria: clinical efficacy of cetirizine in comparison with hydroxyzine and placebo. J Allergy Clinlmmunol. 1990:86:1014-8

58. Zuberbier T, Bindslev-Jensen C, Canonica W, Grattan CE, Greaves MW, Henz BM, et al. EAACI/GA2LEN/EDF. EAACI/GA2LEN/EDF guideline: management of urticaria. Allergy. 2006;61:321-31. 
59. Asero R. Chronic unremitting urticaria: is the use of antihistamines above the licensed dose effective? A preliminary study of cetirizine at licensed and above-licensed doses. Clin Exp Dermatol. 2007;32:34-8.

60. Black AK, Greaves MW. Antihistamines in urticaria and angioedema. Clin Allergy Immunol. 2002;17:249-86.

61. Kozel MM, Sabroe RA. Chronic urticaria: aetiology, management and current and future treatment options. Drugs. 2004:64:2515-36.

62. Weller K, Ziege C, Staubach P, Brockow K, Siebenhaar F, Krause K, et al. H1Antihistamine Up-Dosing in Chronic Spontaneous Urticaria: Patients' Perspective of Effectiveness and Side Effects - A Retrospective Survey Study. PLoS One. 2011;6: 23931

63. Sánchez-Borges M, Caballero-Fonseca F, Capriles-Hulett A. Treatment of recalcitrant chronic urticaria with nonsedating antihistamines: is there evidence for updosing? J Investig Allergol Clin Immunol. 2013;23:141-4.

64. Fedorowicz Z, van Zuuren EJ, Hu N. Histamine H2-receptor antagonists for urticaria. Cochrane Database Syst Rev. 2012;3:CD008596.

65. Grattan CE, O'Donnell BF, Francis DM, Niimi N, Barlow RJ, Seed PT, et al. Randomized double-blind study of cyclosporine in chronic 'idiopathic' urticaria. Br J Dermatol. 2000;143:365-72.

66. Hollander SM, Joo SS, Wedner HJ. Factors that predict the success of cyclosporine treatment for chronic urticaria. Ann Allergy Asthma Immunol. 2011;107:523-8.

67. Di Leo E, Nettis E, Aloia AM, Moschetta M, Carbonara M, Dammacco F, et al. Cyclosporin-A efficacy in chronic idiopathic urticaria. Int $\mathrm{J}$ Immunopathol Pharmacol. 2011;24:195-200.

68. Vena GA, Cassano N, Colombo D, Peruzzi E, Pigatto P; Neo-I-30 Study Group.NeoI-30 Study Group. Cyclosporine in chronic idiopathic urticaria: a double-blind, randomized, placebo-controlled trial. J Am Acad Dermatol. 2006;55:705-9.

69. Hollander SM, Joo SS, Wedner HJ. Factors that predict the success of cyclosporine treatment for chronic urticaria. Ann Allergy Asthma Immunol. 2011;107:523-8.

70. Neverman L, Weinberger M. Treatment of chronic urticaria in children with antihistamines and cyclosporine. J Allergy Clin Immunol Pract. 2014;2:434-8.

71. Kessel A, Toubi E. Cyclosporine-A in severe chronic urticaria: the option for longterm therapy. Allergy. 2010;65:1478-82.

72. Sagi L, Solomon M, Baum S, Lyakhovitsky A, Trau H, Barzilai A. Evidence for methotrexate as a useful treatment for steroid-dependent chronic urticaria. Acta Derm Venereol. 2011;91:303-6.

73. Perez A, Woods A, Grattan CE. Methotrexate: a useful steroid-sparing agent in recalcitrant chronic urticaria. Br J Dermatol. 2010;162:191-4.

74. Asero R. Oral cyclophosphamide in a case of cyclosporine and steroid-resistant chronic urticaria showing autoreactivity on autologous serum skin testing. Clin Exp Dermatol. 2005;30:582-3

75. O'Donnell BF, Barr RM, Black AK, Francis DM, Kermani F, Niimi N, et al. Intravenous immunoglobulin in autoimmune chronic urticaria. Br J Dermatol. 1998;138:101-6.

76. Pereira C, Tavares B, Carrapatoso I, Loureiro G, Faria E, Machado D, et al. Lowdose intravenous gammaglobulin in the treatment of severe autoimmune urticaria. Eur Ann Allergy Clin Immunol. 2007;39:237-42.

77. Mitzel-Kaoukhov H, Staubach P, Müller-BrenneT. Effect of high-dose intravenous immunoglobulin treatment in therapy-resistant chronic spontaneous urticaria. Ann Allergy Asthma Immunol. 2010;104:253-8.

78. Maurer M, Altrichter S, Bieber T, Biedermann T, Bräutigam M, Seyfried S, et al. Efficacy and safety of omalizumab in patients with chronic urticaria who exhibit lgE against thyroperoxidase. J Allergy Clin Immunol. 2011;128:202-209.e5.

79. Khan DA. Alternative Agents in Refractory Chronic Urticaria: Evidence and Considerations on Their Selection and Use. J Allergy Clin Immunol Pract. 2013:1:433-440.e1

80. Saini S, Rosen KE, Hsieh HJ, Wong DA, Conner E, Kaplan A, et al. A randomized, placebo-controlled, dose-ranging study of single-dose omalizumab in patients with H1-antihistamine-refractory chronic idiopathic urticaria. J Allergy ClinImmunol. 2011;128:567-73.e1

81. Maurer M, Rosén K, Hsieh HJ, Saini S, Grattan C, Gimenéz-Arnau A, et al. Omalizumab for the treatment of chronic idiopathic or spontaneous urticaria. N Engl J Med. 2013;368:924-35.

82. Asero R, Tedeschi A, Cugno M. Treatment of chronic urticaria. Immunol Allergy Clin North Am. 2014:34:105-16.

83. Chakravarty SD, Yee AF, Paget SA. Rituximab successfully treats refractory chronic autoimmune urticaria caused by $\operatorname{lgE}$ receptor autoantibodies. J Allergy ClinImmunol. 2011;128:1354-5.

84. Arkwright PD.Anti-CD20 or anti-IgE therapy for severe chronic autoimmune urticaria. J Allergy Clin Immunol. 2009;123:510-1.

85. Mallipeddi R, Grattan CE. Lack of response of severe steroid-dependent chronic urticaria torituximab. Clin Exp Dermatol. 2007:32:333-4.

86. Wilson LH, Eliason MJ, Leiferman KM, Hull CM, Powell DL. Treatment of refractory chronic urticaria with tumor necrosis factor-alfainhibitors. J Am Acad Dermatol. 2011;64:1221-2.

87. Piconi S, Trabattoni D, lemoli E, Fusi ML, Villa ML, Milazzo F, et al. Immune profiles of patients with chronic idiopathic urticaria. Int Arch Allergy Immunol. 2002:128:59-66.

88. Hermes B, Prochazka AK, Haas N, Jurgovsky K, Sticherling M, Henz BM Upregulation of TNF-alpha and IL-3 expression in lesional and uninvolved skin in different types of urticaria. J Allergy Clin Immunol. 1999;103:307-14.

89. Reeves GE, Boyle MJ, Bonfield J, Dobson P, Loewenthal M. Impact of hydroxychloroquine therapy on chronic urticaria: chronic autoimmune urticaria study and evaluation. Intern Med J. 2004;34:182-6.

90. Pho LN, Eliason MJ, Regruto M, Hull CM, Powell DL. Treatment of chronic urticaria with colchicine. J Drugs Dermatol. 2011;10:1423-8.

91. Noda S, Asano Y, Sato S. Long-term complete resolution of severe chronic idiopathic urticaria after dapsone treatment. J Dermatol. 2012;39:496-7.

92. Engin B, Ozdemir M. Prospective randomized non-blinded clinical trial on the use of dapsone plus antihistamine vs. antihistamine in patients with chronic idiopathic urticaria. J Eur Acad Dermatol Venereol. 2008;22:481-6.

93. Khan S, Lynch N. Efficacy of montelukast as added therapy in patients with chronic idiopathic urticaria.Inflamm Allergy Drug Targets. 2012;11:235-43.

94. Criado PR, Antinori LC, Maruta CW, Reis VM. Evaluation of D-dimer serum levels among patients with chronic urticaria, psoriasis and urticarial vasculitis. An Bras Dermatol. 2013;88:355-60.

95. Asero R, Tedeschi A, Cugno M. Heparin and tranexamic Acid therapy may be effective in treatment-resistant chronic urticaria with elevated d-dimer: a pilot study. Int Arch Allergy Immunol. 2010;152:384-9.

96. Samarasinghe V, Marsland AM. Class action of oral coumarins in the treatment of a patient with chronic spontaneous urticaria and delayed-pressure urticaria. Clin Exp Dermatol. 2012;37:741-3.

97. Chua SL, Gibbs S. Chronic urticaria responding to subcutaneous heparin sodium. Br J Dermatol. 2005:153:216-7.

98. Parslew R, Pryce D, Ashworth J, Friedmann PS. Warfarin treatment of chronic idiopathic urticaria and angio-oedema. Clin Exp Allergy. 2000;30:1161-5.

99. Karaayvaz M, Calişkaner Z, Turan M, Akar A, Oztürk S, Ozangüç N. Levothyroxine versus ketotifen in the treatment of patients with chronic urticaria and thyroid autoimmunity. J Dermatolog Treat. 2002;13:165-72.

100. Temboury Molina C, AlinsSahún Y, Cerecedo Carballo I. [Recurrent urticaria and autoimmune thyroiditis: the influence of thyroxin treatment on the outcome of the urticaria]. An Pediatr (Barc). 2012;77:66-7.

101. Gupta MA, Gupta AK. Chronic idiopathic urticaria and post-traumatic stress disorder (PTSD): an under-recognized comorbidity. Clin Dermatol. 2012;30:351-4.

102. Hunkin V, Chung MC. Chronic idiopathic urticaria, psychological co-morbidity and posttraumatic stress: the impact of alexithymia and repression. Psychiatr $Q$. 2012;83:431-47

103. Staubach P, Dechene M, Metz M, Magerl M, Siebenhaar F, Weller K, et al. High prevalence of mental disorders and emotional distress in patients with chronic spontaneous urticaria. Acta Derm Venereol. 2011;91:557-61.

104. O'Donnell BF. Urticaria: impact on quality of life and economic cost. Immuno Allergy Clin North Am. 2014;34:89-104.

105. Rabelo-Filardi R, Daltro-Oliveira R, Campos RA.Parameters associated with chronic spontaneous urticaria duration and severity: a systematic review. Int Arch Allergy Immunol. 2013;161:197-204.

106. Sánchez-Borges M, Asero R, Ansotegui IJ, Baiardini I, Bernstein JA, Canonica GW, et al. Diagnosis and treatment of urticaria and angioedema: a worldwide perspective. World Allergy Organ J. 2012;5:125-47.

107. Ye YM, Jin HJ, Hwang EK, Nam YH, Kim JH, Shin YS, Co-existence of chronic urticaria and metabolic syndrome: clinical implications. Acta Derm Venereol. 2013;93:156-60.

MAILING ADDRESS:
Vitor Manoel Silva dos Reis
Av. Dr. Enéias de Carvalho Aguiar $2553^{\circ}$ andar-
Dermatologia
05403-000 - São Paulo - SP
Brazil
E-mail: vitoreis76@hotmail.com

MAILING ADDRESS:

Vitor Manoel Silva dos Reis

Av. Dr. Enéias de Carvalho Aguiar $2553^{\circ}$ andar -

05403-000 - São Paulo - SP

E-mail: vitoreis76@hotmail.com

How to cite this article: Criado PR, Criado RFJ, Maruta CW, Reis VMS. Chronic urticaria in adults: state-of-the-art in the new millennium. An Bras Dermatol. 2015;90(1):74-89. 